\title{
El Paisaje en la Literatura Americana, Clemento Desconocido Aunque Dominante
}

\begin{abstract}
A exposición o enseñanza de la literatura americana suele 11 concretarse, como otras, al resumen de las obras escritas, de la biografía de sus autores $y$, a veces, del ambiente histórico en que se produjeron. Cuando se habla de la naturaleza, ello es en términos de geografía: tal como si al describir un drama se limitase el descriptor a enumerar, como notario o albacea, los objetos presentes bajo su retina. La sensación, el paisaje permanente intocados; la sensibilidad, inédita. Sin embargo, la literatura se refiere a la sensibilidad antes que al entendimiento, como toda arte. Bueno será recordarlo permanentemente.
\end{abstract}

Si el paisaje puede diluirse ahí donde no tiene tanta vigencia, en cambio su mera borrosidad o rebajamiento infiere insustituíble merma a la comprensión - y sensación- de América. Nosotros somos el continente del Paisaje Triunfante. Por tanto, desentendernos de él, es como echar por la borda brújula, cuaderno de bitácora y carta de navegación, y, luego, discutir el mandato de viento y ola.

Cuando uno examina, aunque resbalando sobre la superficie de las cosas, algunas literaturas extranjeras, se da cuenta de que el paisaje, aunque soslayado a veces, es un factor primordial de toda personalidad estética, más aún, humana. No es preciso que Cervantes se detenga mucho en describir- 
nos los senderos y llanuras de la Mancha, sino que simplemente lo roce, para que Flaubert diga que al leer el Quijote no podía perder de vista su paisaje. En todas las letras frrancesas persiste el ambiente: bien sea el citadino con su Sena perezoso y sus "quais" evocadores, o bien las llanuras ubérrimas de Normandía, o los cielos foscos de Bretaña que, alguna vez, se atreven a mezclarse con los nuestros, cual aparece, verbigracia, en aquel cuadro de Tito Salas que retrata "El éxodo" del Libertador Bolívar, en tierra caliente caraqueña bajo un plomizo cielo bretón.

Pero, no es de esto, que ya cae dentro de la órbita de la sensibilidad del artista, de lo que quiero hablar aquí, sino de aquello que entraña un planteamiento sistemático; aquello que implica la posición del crítico y del pedagogo, entendido, por cierto, que ambas funciones, lejos de completarse, se diversifican y hasta se repelen. Los profesores de literatura debieran, por tal razón, velar permanentemente sobre sus armas, para no dejarlas mellar bien por la rutina de la vulgarización (en que estriba sus prestigios la didaxia), bien por el ácido creador - y corrosivo- de la crítica, que es interpretación y, por consiguiente, recreación.

La pregunta que se plantea, de consiguiente, debe ser propuesta de manera metódica, aunque ella pueda admitir -y admita - versiones arbitrarias.

Podría decir así ies el paisaje nada más que un escenario en que se desarrolla la literatura o es como un protagonista - como la sangre, como la costumbre, como las creencias - cuya presencia significa acción y no mera pasión? Si tratándose de otras literaturas, quizá aparezca a menudo la duda, tratándose de la americana no vacilo un punto, y contesto resuelio y terminante: lo segundo es lo exacto.

Pero, ¿cómo se prueba esa acción del paisaje y qué alcance tiene ello tanto para la interpretación (crítica) y la vulgarización (didáctica) de nuestra expresión espiritual escrita? De ambos temas quisiera tratar aquí dentro del marco más estrecho posible, dando así, por fuerza de las circunstan. cias, singular valor compendioso a cada juicio y a cada proposición. 
La acción del paisaje, en función de protagonista, me parece innegable no bien se asoma uno a la literatura americana. Recordemos, por no citar sino hitos, que hasta los poetas de la conquista, Balbuena o Castellanos, se deleitaban en describir, en enumerar, en pintar.

No pocas veces el más seco cronista, de esos que llegaban con ánimo captor, cedió el paso al pasmo que la naturaleza despertaba en él, posponiendo cuestiones apremiantes, problemas de captura y aprovechamiento, por dar rienda suelta a la lujuria de su retina. El adusto Cieza de León consagra toda una parte de su Crónica del Perú (la primera) a describir nuestros valles. No diré nada de Ercilla, del Inca Garcilaso, que a cada instante interrumpe sus relatos para permitir acceso a ellos a la naturaleza, centinela constante a la puerta de su sensibilidad; y que comienza sus Comentarios con la "Descripción del Perú". El propio Pedro de Valdivia, narrador nada florido, aquejado de perenne ansia de indemnizaciones pecuniarias, suelta por ahí, en una carta a Carlos $V$, fechada en 1545, un párrafo sobre la tierra chilena, que es un convite a lanzarse a ella y un mentís al desconsuelo que acarrearon al respecto los compañeros del infortunado Almagro. $Y$ hasta el tudesco Schmidel, ese soldadote ingenuo que llama "Manthossa" a Mendoza y apenas acierta en los vocablos más precisos, se deja alguna vez arrebatar —como también el aventurero Cabeza de Vaca-por la bulimia de condensar el paisaje en una página de su memorial.

Mas, se dirá: aquello era noviazgo y nada más. Gente que llegaba y se hería con tanto verde y tanto sol. Pasado el noviazgo, fué lo mismo. $\mathrm{Y}$ si algo mitigó aquello fué el apoltronamiento colonial, en cuya virtud las retinas salieron a busear panorama en los libros, y volvieron - tiempo de minería- cargadas de perlas y topacios, amatistas, zafiros, carbunclos, diamantes, jaspes, ópalos y berilos. De ello dan buena prueba no sólo los poemas cortesanos, sino también los eclesiásticos, de intención devota: La Cristiada de Hojeda, los poemas de Sor Juana Inés.

Podríamos seguirle la pista al paisaje, como héroe de una epopeya dispersa y varia, si no hubiera mayor interés en 
abordar la segunda cuestión. Sobre la primera bastaría recordar que, en los albores mismos de la Independencia, Olmedo, por citar sólo al poeta dilecto de Bolívar, y ya en zona intermedia, intertropical si se quiere, Olmedo utiliza las cumbres, el sol, los llanos para glorificar al vencedor de Junín; que esa beligerancia ininterrumpida del mundo exterior actúa, como personaje, en la obra de Isaacs, de José Eustasio Rivera, del propio José Asunción Silva - según lo acaba de mostrar en afortunado ensayo Carlos García-Prada-; en los brasileños todos: Machado de Assis, Bilac, Aranha hasta Da Cunha y Amado; en los mexicanos - si bien algo atenuada por la mayor importancia del hombre-desde Flores hasta Gutiérrez Nájera, desde Acuña hasta González Martínez, desde Lizardi hasta López Velarde, cuya "Suave Patria" diríase la protagonización vegetal del solar nativo. Esta naturaleza estalla en ditirambos a minerales, metales y flora en la poesía chilena - Mistral, Neruda, Juvencio Valle, por citar a los de ahora, sin preterir las descripciones coloniales de Ercilla, de Oña, de Núñez de Pineda Bascuñán y Ovalle, de Lillo, de Latorre, e inspira las églogas de Teresa de la Parra y Julián Padrón, en Venezuela, y las epopeyas de Gallegos, y, antaño, los versos de Pérez Bonalde. $Y$ revienta en flor de mil pasajes de Martí, y en toda la literatura argentina, a ratos tan española por el sabor de austeridad que da a la tierra, sin el fervor pánico del trópico, con una como tascada convicción de que el primer peldaño se coloca sobre el suelo, y que juntas se alzan pared y enredadera. Desde José Hernández hasta Fernando Gilardo, desde Payró y Lynch hasta Güiraldes, pampa y ombú — también señoriales en Hudson- dirigen aquella sinfonía unfinished. Y en el Perú, no obstante nuestra falta de ojos para ver, se nos mete el agro en la literatura con la Matto de Turner, como lejano inicio, pero se sublimiza con Valdelomar y con Alegría, con Arguedas y a veces con Gálvez, con López Albújar y con Valcárcel, con Xammar y con Valle Goicochea.

La presencia del paisaje no es de las que se disluyen, ni se resigna a ser telón de fondo background de una literatura. Al modo de la calle en una novela de Pirandello, o del tambor en un drama de O'Neill, o del silencio en esa dulce 
"Clara D'Ellebeuse" de Francis Jammes, el paisaje nuestro actúa por presencia y por influencia. Es y está y hace y dice y presiona y preside y plasma. Lo cual, en buena cuenta, viene a confirmar la aserción de Keyserling cuando nos denomina "continente del tercer día", en el cual la Sargre y lo Telúrico traban desigual lucha ya que, por hoy, este último seguirá venciendo a aquél hasta que se establezca - no se restablezca: se establezca- el equilibrio y comencemos nuestra vida, súbitamente saltada, no ya de cuarto, sino de séptimo día.

Tratemos, ahora, del alcance - no ya de la presenciadel paisaje en nuestra literatura. $Y$ para ello habremos de caminar con cierto orden.

La Colonia vivió enquistada en las ciudades que trataron de remedar a las Cortes europeas, singularmente a la madrileña, $y$, a través de ella, entrado el siglo XVIII, a la de Versalles. Dispensábase la cultura nada más que en las ciudades, $y$, concretando: en ciertas ciudades. Siendo tan reducido el ámbito ilustrado, reducido en lecturas, reducido en lectores, reducido en autores, reducido en facilidades de imprenta, el sector literario cobra petulancia y hermetismo, dos rasgos inherentes al escriba y, por ende, a la casta. Su miraje se circunscribe a lo inmediato.

La erudición reemplaza a la sensibilidad. La cita a la contemplación. La lectura al paisaje. Ergo: el panorama se convierte en una estela de infolios, de elzevires, de pergaminos, de papel, impreso o simplemente caligrafiado.

Después del pasmo del descubrimiento, evidente en los cronistas, la naturaleza no aflora sino en los enciclopedistas, que se dejan arrebatar nuevamente por el señuelo de la geografía. No olvidemos que nuestra primera forma de nacionalismo rompe a andar bajo el impulso del andarinaje. Verdad que ya se escuchan los rumores de Rousseau y su ralea heterodoxa. Como quiera que fuese, ello comporta una ruptura con el despotismo totalitario del libro.

Para nosotros, el paisaje amanece con el prerromanticismo, y otra vez vemos aparecer caminantes que usan carreta, báculo, ironía y papel. No es vana coincidencia el que 
aparezcan, con pequeña distancia cronológica, Labardén, en el río de la Plata con su "Oda al Paraná", "Concolorcorvo", con su Lazarillo de ciegos caminantes, entre Buenos Aires y Lima; Lizardi en Nueva España; el centroamericano Landívar, al par que los viajeros franceses y alemanes, sobre todo La Condamine y Humboldt, todos ellos obsedidos ya por la naturaleza. Los escritores que, luego, amanecen, bien sea como eco de esta tendencia prerromántica e enciclopedística, bien como una resonancia de Chateaubriand, en quien hierve el ímpetu sentimental, y de Saint-Pierre, inciden en la misma devoción por el paisaje: don Andrés Bello no se escapa, pese a su clasicismo, de semejante señuelo, y su "Oda a la Agricultura de la Zona Tórrida" es una elocuente muestra de lo que vengo diciendo.

A partir de este instante, la beligerancia del paisaje va tapando todo aquello que no rezuma política. Cuando el escritor se libra de la tentación inmediata, de la alusión personal, de lo chico pero cercano, corre a refugiarse en el panorama. Mejor dicho: corre él, abre simplemente los brazos para comulgar con el paisaje, para absorberse en él.

De todos modos, porque se trata en no escasa parte de algo imitativo y rapsódico, este paisajismo le toma sabor antes que nada a los elementos decorativos de lo circundante. Por tanto, maneja un paisaje subsidiario, adjetivo, en el cual pueden alzarse, con el tinglado eminente, los discursos, más que las pasiones, de los personajes románticos. Y ocurre, entonces, que poseyendo un escenario enorme y policromo, sentidor y sentido, lo suplanta limpiamente el que surge del cotejo con otros medios, como si nuestro sino consistiera en ir en busca de los mares, caracola en mano, para deleitarnos con la indirecta y empequeñecida resonancia de su tumulto en la oquedad de nácar.

Tomemos cualquier ejemplar de nuestro romanticismo para explicarse mejor: Ricardo Palma, tradicionista de fama extensa y merecida.

En Palma confluyen gracia y conocimiento histórico. $\mathrm{Su}$ obra se mueve en el tiempo pasado, mejor que en el presente. Inaugura un humor nuevo: el donaire ante la evocación o la 
remembranza bienhumorada. Pero, el paisaje no existe ahí. Tampoco se hace presente en sus versos. Pinturas de personas, sí, y llenas de picardía, de exactitud, de relieve; mas la naturaleza se difuma. En algún rato, cuando describe a Huamanga o a la misma Lima uno pediría que algún rasgo diera la impresión, siquiera remota, del cielo y el monte, pero el escritor pasa de largo y describe una escena, pinta a un tipo, narra un episodio, y luego desaparece.

Sin embargo, los poetas y prosadores románticos no siguen esta norma, a menudo se deleitan en alusiones y "descripciones" del cielo y del mar (la tierra inspira poco, tal vez porque es más tangible). Un cielo fulgente, adecuado a los sentimientos que experimenta o pretende inspirar el escritor; un mar también hecho a la medida del estado de ánimo (no al revés) del espectador, de suerte que entre mar y cielo bien podían decir al artista mon semblable et mon freve.

Tal similitud, insisto, procede de modo inverso: no del ambiente al personaje, sino del personaje al ambiente, como si se tratara de un fecundo demiurgo, hacedor de bienes y males, especie de pequeño dios ante cuyos antojos se doblega la naturaleza $0 .$. que simplemente elabora una naturaleza a la medida de sus apetencias o necesidades.

La tierra aparece en la literatura americana con el realismo. A fines del siglo XIX, cielo y mar empiezan una rápida retirada, nada estratégica, ante el avance de la tierra. Cierto que en tal período ocurren sucesos que rompen el idilio de la ola y el éter: las guerras que comprometen a cinco naciones entre 1863 y 1866 ; y a siete entre 1870 y 1880 , revelan, de pronto, al hombre de la calle del continente al imperio de fuerzas que él miraba de soslayo. Aprende a caminar sobre el suelo, asentando la planta; a considerar al hombre dejando un tanto ciertas categorías establecidas por el virreinam to y mantenidas por los neovirreinales de la República. Sin caer en la proclama de tipo social, dentro del escueto terreno de los hechos, cito esos acontecimientos porque ellos ocurrieron, sin que en su ocurrencia hayan tenido participación nuestra interpretación, nuestro deseo ni nuestros prejuicios.

Con todo, el paisaje de los realistas todavía continúa siendo a modo de telón de fondo. Subsiste una especie de 
concepto teórico-positivista de la realidad. Algunos hablan -González Prada, por ejemplo- de un estilo claro "como un alcohol rectificado". Ese mismo gran humanista, hasta cierto punto gran colonialista, que fué Juan Montalvo, mezcla en curiosa dosis la metáfora renacentista, el ejemplo grecorromano y los vocablos que la ciencia pone en circulación. Mias, de todos modos, la tierra con su presencia trae un hálito de solidez, de humanidad, de certidumbre que el lejanismo romántico (la lejanolatría) no poseyó jamás. Pastaría comparar - saltando por sobre ciertos precursores, como Sarmiento- el registro de los novelistas argentinos de ese tiempo (López, Leguizamón, Cambaceres) y el de los mexicanos de igual etapa, y hasía la incipiencia novelística peruana, y el surgir de la novela chilena realista, para darse cuenta de que, aunque encerrada en las ciudades, aunque incipientemente afrancesada y forzadamente nativista, el contacto con la tierra reviste de singular vigor, de tangibilidad extraordinaria a la literatura finisecular y naturalista.

Con todo, el paisaje parece todavía ignorado o adormecido.

Es como un huésped inevitable, a quien reciben de mala gana el novelista $y$, a veces, hasta el poeta. $Y$ cuando le brindan la mano cordialmente, se advierte que al punto el invitado se trepa a la cabeza del invitante y se adueña de él. El caso de Chocano es, al respecto, en grado sumo instructivo. El de José Eustasio Rivera pertenece a otro tipo de sensibilidad. Y el de Luis Carlos López así como el de Fernández Moreno se hallan dominados por el ambiente, citadino, por una naturaleza que es más bien milieu, ambiente, que protagonista ella misma.

Yo he dicho alguna vez - y me cito no por vanagloria, sino por precisar mejor la cronología (para mí) del asertoque una de las notas características del novelista indoamericano reside en su sumisión ante el paisaje. Lo que vengo anotando parece una negación de ello. No lo es.

La sumisión a que me refiero tiene dos tiempos: uno, aquel a que he aludido, o sea el en que la naturaleza, el paisaje, se asomaba pasando por encima del embeleso foráneo del sor'tilegio externo, de la cultura epidérmica del autor, de 
su sensibilidad a flor de libro; y dos, el que, avasallando esa muralla de eruditismo y prevención europeísta, derriba el muro de la imitación y trata de expresarse en su esencia.

Este segundo período es el de la sumisión mencionada. Pero ¿por qué sumisión?

Ante todo, describamos el fenómeno.

A fines del siglo XVIII parece como que se redescubrió el paisaje americano. Mas, con la independencia, aquellos primeros vagidos de descriptivismo, cesaron. Con la república sobrevino la avalancha romántica. La lontananza se erigió en numen tutelar de nuestra inspiración. Lo inmediato perdió su vigencia. Esa censura -o pausa - duró hasta que se estableció el realismo, a fines del pasado siglo, y entonces, al trocar el cielo y el mar por la tierra sólida y precisa, recomienza el proceso interrumpido en 1800. Cien años habían sido necesarios para rectificar semejante yerro.

Pero, el recomienzo de 1900 y tantos, posado ya sobre firmes bases, sobre el suelo, adquirió en seguida un impulso considerable. La naturaleza, además, había abierto arcanos ignotos. La selva amazónica, la selva misionera, la cumbre y su influencia, la pampa como ingrediente de vida nunca fueron trajinadas ni literaria ni humanamente. A lo sumo carretas de inmigrantes, partidas de soldados, incivilizadas huestes de indios primitivos, pero ninguna otra inquietud contemporánea. Desde fines del 800 esto empezó a cambiar. Con el 900 se tuvo conciencia del cambio. Y los escritores experimentaron el "embrujo" — perdonado he de estar por Carlos Reyles- de la tierra nativa.

Toda la novela americana típica y casi toda la poesía típica también (la del negro cubano, la del naturalismo órfíco de los chilenos, la de la nostalgia argentina, la del indigenismo y el cholismo peruanos, etc.) se nutren a los pechos de la tierra recién descubierta, y de su encarnación, el personaje criollo, también recién avalorado.

Si repasamos las obras fundamentales de nuestras letras, hallaremos que en ellas la naturaleza, el paisaje tiene una actitud de prima donna. Enumeraré: La vorágine, Doña Bârbara, Canaima, Cuatro años a bordo de mí mismo, La ser- 
piente de oro, Jubiabá, Las lanzas coloradas, Canaan, El caballero Carmelo, Matalaché, Zurzulita, Ifigenia, Candelas de verano, Don Segundo Sombra, La carreta, Silvano Corujo, $R a z a$ de bronce, por mencionar aquellas que más pronto han acudido a mi memoria, barajando los nombres de Eustasio Rivera, Rómulo Gallegos, Eduardo Zalamea Borda, Ciro Alegría, Arturo Uslar Pietri, Jorge Amado, Graça Aranha, Abraham Valdelomar, Enrique López Albújar, Mariano La. torre, Teresa de la Parra, Julián Padrón, Ricardo Güiraldes; Enrique Amorim, Fernando Gilardi, Alcides Arguedas (y agreguemos a José Rubén Romero y, a veces, a Azuela, Mag. daleno y López y Fuentes).

$\mathrm{Y}$ en poesía ocurre algo semejante, según se ha dicho en páginas anteriores.

Mas, ¿cuál es lo extraordinario en todo esto?

Lo extraordinario consiste en que, a diferencia del esoritor europeo, el indoamericano no sabe conducir al paisaje, sino que se deja determinar por él. Con lo cual entramos al punto final de mi tesis y a su resumen.

Enumeraré para parecer doctoral:

1.-.-Tanto la literatura norteamericana (o saxoamericana) como la indoamericana se diferencian de la europea en que en ambas el escritor actúa como medium, inapto para dominar el tumulto de la ciudad y los implementos de progreso (la primera) y de la naturaleza (la segunda).

Quisiera acotar: Sinclair Lewis o John Dos Passos, o Dreiser o Hemingway acusan caos en su obra. Lo mismo Pearl Buck. Igual Upton Sinclair, Sherwood Anderson, Eugene O'Neill, Waldo Frank. Se ve que tienen más mundo qué contar que método con el cual proceder. Cosa análoga ocurre entre los indoamericanos, sustituyendo la Calle Mayor por la selva o la pampa o el rio; el club de solteronas por la cantina; el cheque por la carabina; el auto por el caballo; el chewing gum por el mate, la mariguana, la coca, etc.

$2^{\circ}$ - Todo escritor europeo, por insignificante que sea, empieza por el plan y se somete a él, es decir, se somete a sí mismo, puesto que el plan resulta su propia obra. El escritor americano (saxo o indo) aunque tenga un plan da la 
impresión de desgreñado por abundancia de cabello. No es descuido, es abundancia o sea insuficiencia de los medios para sujetar tanta sustancia. Poco peine y mucho cabello.

$3^{\circ}$-Estos dos hechos confluyen en un tercero: es imposible estudiar la literatura americana sin penetrar en su paisaje, sin examinar la acción de lo telúrico sobre su intérprete, sin establecer ciertas coordenadas (predominio de mar, de llanura, de selva, de valle, de trópico, de polo) que sirven para diferenciar - sin desunir ni extirpar el acento de familia común a todo- los caracteres típicos de cada literatura, así como, por ejemplo, en la francesa, hay un tono provenzal, un tono bretón, un tono parisiense.

En suma, que, junto a la valoración histórica y social se hace indispensable (prescindiendo de toda imitación de Taine, que exageraba la nota) considerar el paisaje o la naturaleza, en su triple función estética:

a) como escenario en el cual ocurren ciertos hechos;

b) como actor que determina ciertos acaecimientos, y

c) como acaecimiento en sí.

Santiago, junio de 1940.

Luis Alberto Sánchez. 
